\title{
Effects of Physical Exercise on Burnout Syndrome in University Students
}

\author{
Yury Rosales-Ricardo MS PhD and José P. Ferreira MS PhD
}

\begin{abstract}
INTRODUCTION Burnout syndrome has a negative impact on university students' health worldwide. Global prevalence of each dimension of the syndrome is estimated at $55.4 \%$ for emotional exhaustion, $31.6 \%$ for cynicism and $30.9 \%$ for academic inefficacy.
\end{abstract}

OBJECTIVE Evaluate the efficacy of physical exercise in reducing burnout levels in university students.

METHODS We carried out an investigation in students from the Technical University of Ambato, Ecuador. Students were in different career tracks, randomly selected, and were assigned to three different groups with pre-test and post-test measurements: two intervention groups (aerobic and strength exercise) and one control group (no exercise). The evaluation instrument was the Maslach Burnout Inventory-Student Survey, whose dimensions are

\section{INTRODUCTION}

Burnout syndrome (BS) is a health issue with great-and often underacknowledged-societal repercussions. In students, BS is defined as a persistently negative emotional response related to being a student, which consists of feelings of tiredness, not being able to perform study-related tasks (exhaustion); a cynical or detached attitude regarding the meaning and utility of studies undertaken (cynicism); and a feeling of academic incompetence (inefficacy). BS is measured with the Maslach Burnout InventoryStudent Survey (MBI-SS), which incorporates these dimensions.[1]

BS has broadened as a field of study, as research is now carried out on university students,[1] since they face pressures and overloads related to academic work, like workers with their specific work. [2] Additionally, they are exposed to many demands concerning their educational context: learning, academic performance, work overload, time pressure and paucity, lack of self-management opportunities, competition among peers, perceived irrelevance, poor teaching and poor relationships, among others, and in the academic environment, students are considered among the most vulnerable to BS.[1-4]

Global prevalence of BS dimensions in students is estimated at $55.4 \%$ for emotional exhaustion, $31.6 \%$ for cynicism and $30.9 \%$ for academic inefficacy.[1,2]

\section{IMPORTANCE}

This is the first study in Latin America and among the first worldwide demonstrating the benefits of physical exercise in reducing burnout levels in university students. exhaustion, cynicism and academic inefficacy. We also evaluated heart rate variability.

RESULTS The aerobic exercise group reduced cynicism by $21.1 \%(d=0.252)$, inefficacy $13.1 \%(d=0.397)$ and exhaustion by $31.0 \%(d=0.532)$. The strength exercise group reduced cynicism by $27.4 \%(d=0.315)$, inefficacy by $21.7 \%(d=0.704)$ and exhaustion by $19.6 \%(\mathrm{~d}=0.299)$. In the control group, exhaustion and inefficacy increased by $10.1 \%(d=0.128)$ and $4.4 \%(d=0.129)$ respectively; instead, cynicism was reduced by $7.3 \%(d=0.062)$. The aerobic exercise group had the greatest increase in heart rate variability (at 16.8\%), followed by the strength group (16.6\%) and the control group (5.2\%).

CONCLUSIONS Physical exercise (both aerobic and strength) was effective in reducing burnout levels in university students.

KEYWORDS Exercise; burnout, psychological; burnout, professional; mental health; Ecuador

The practice of regular physical exercise has beneficial effects for overall physical,[3,4] mental[4,5] and socio-affective[5] health. It directly supports mental health, as the endorphins released during physical exercise act on the brain and produce sensations of well-being and immediate relaxation;[6] in addition, they inhibit the neurotransmitters that transmit pain, resulting in analgesia and mild sedation. We also observed reductions in stress and emotional fatigue, which in turn can lead to better sleep quality and improved well-being, and decreased BS and fatigue.[6] Regular physical exercise could be an effective intervention to reduce burnout in students.

In the absence of an effective physical exercise program, students may suffer from mental health problems with their studies, because the risk of mental health issues increases if academic studies are accompanied by certain predisposing factors.[6]

Programs designed to prevent or treat BS are essential in improving student health, and yet to date, few studies have been conducted on the usefulness of physical exercise in combatting BS in university students,[5] the objective of our research.

\section{METHODS}

Study and participants We carried out an investigation from January through October, 2018 in students from the Technical University of Ambato, Ecuador, which at the time of our study enrolled 13,000 students. A sample of 1600 undergraduate students from all departments, career tracks and years of study was selected via stratified random sampling. MBI-SS was administered to students by a psychologist qualified to do so.[7,8] Among the students selected, 461 had moderate or high levels of BS; 380 students were excluded for various reasons (incom- 
plete $\mathrm{MBI}-\mathrm{SS}$ and heart rate variability evaluations, illness, movement difficulties) leaving a total sample of 81 students. These students were randomly divided into three similarly composed groups: two intervention groups (aerobic and strength-training exercises) and a control group (no assigned exercise). The mean age of the control group was 23.13 years (SD $=3.77$ ), that of the aerobic exercise group was 22.74 $(S D=3.05)$, and that of the strength-training group was 22.97 (SD = 3.31) (Figure 1).

\section{Study variables}

Burnout syndrome in students was evaluated using the MBI-SS, $[1,8]$ structured to evaluate three dimensions: the feeling of not being able to give more of oneself, both physically and psychically (exhaustion), devaluation and loss of interest in studying (cynicism) and doubts about one's ability to carry out efficacious academic work (inefficacy). All items in each of these subscales were scored on a 7-point frequency scale, ranging from 0 (never) to 6 (always). Of the items, 5 evaluate exhaustion, 4 cynicism, and 6 academic inefficacy, for a total of 15 items. The scale has adequate levels of global internal consistency ( $\alpha$ $=0.82$ ) and validity as measured by the Kayser, Meyer \& Olkin test $(\mathrm{KMO}=0.87) .[8]$

The scale was evaluated according to the following:[7,8]

- Exhaustion: No BS: <1.2; Low: 1.3-2.0; Moderate: $2.1-2.8$; High: $\geq 2.9$

- Cynicism: No BS: <0.5; Low: 0.6-1.24; Moderate: $1.25-2.25$; High: $\geq 2.26$

- Inefficacy: No BS: <2.83; Low: 2.83-3.83; Moderate: 3.84-5.16; High: $\geq 5.17$

Heart rate variability (HRV) is a good marker of overall health status and can quickly aid in the diagnosis of states of stress, burnout, fatigue, overtraining, exhaustion, or anxiety in the general population. It is an excellent cardiovascular biomarker for prevention and early detection of BS.[9] To measure HRV, a transmitter band and the Android application Elite HRV were used, by which the mean (RR), standard deviation (SDNN) and square root of the mean value of the sum of the squares of the difference of all RR intervals (RMSSD) are generated between $R$ waves with each heartbeat.

Physical exercise Our definition and procedures regarding physical exercise were taken from the American College of Sports Medicine's (ACSM) latest prescribed exercise guidelines.[10]

Procedures The 81 study participants were randomly assigned to one of the three groups, as previously described: two intervention groups (one assigned aerobic physical exercise and one assigned resistance/strength-training exercise) and a control group, to which no treatment was applied (Table 1). In the two exercise groups, physical exercise was governed by the latest
Figure 1: Study protocol flowchart

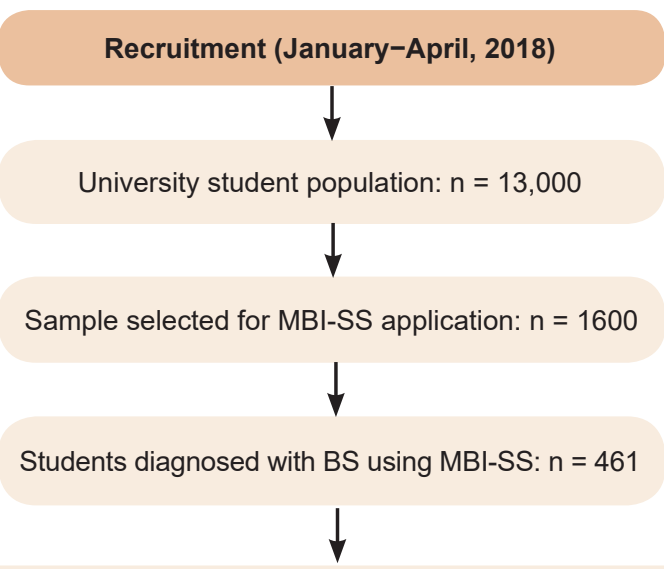

Students remaining after 380 were excluded for various reasons (incomplete MBI-SS or HRV

evaluations, illness or difficulty moving) who agreed to participate in the study: $n=81$

$\downarrow$

Assignment and Follow-up (May-September, 2018)

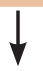

Aerobic exercise group $\mathrm{n}=28$

- Students who performed assigned - Students who did not cises (did not regularly attend sessions, $n=2$ )

Students analyzed: $\mathrm{n}=26$

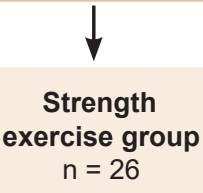

- Students who performed assigned exercises $(n=25)$ - Students who did not perform assigned exercises (did not regularly attend sessions, $n=1$ )

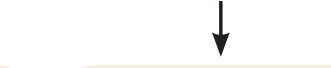
exercise) $\mathrm{n}=27$

- Students who performed no exercise $(n=27)$ - Students who participated in evaluations $(n=27)$

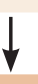

Analysis (October 2018)

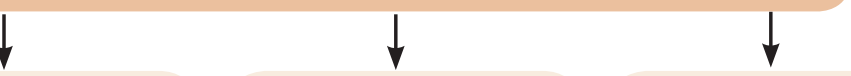

Students analyzed: $n=25$

Students analyzed: $n=27$

ACSM prescribed exercise guidelines[10] at three weekly sessions of one hour on alternating days for 16 weeks, always from 5:00 PM to 6:00 PM.[9] The MBI-SS was applied at the beginning of the study, and HRV was measured in all participants. The two instruments (MBI-SS and HRV) were reapplied to the 3 groups at week 17, and comparisons were made between groups.

The aerobic exercise group was assigned jogging, walking or stationary bicycling for 30-50 minutes, divided into an initial warmup/stretch, the planned aerobic exercise, and a recovery period. [10] The strength/resistance training group was assigned pushups, abdominal exercises, high bar and leg squats, in sessions of 30-50 minutes, divided into warm-up and stretching, planned strength exercises, and a recovery period.[10] No exercises were assigned to the control group. 
Data analysis All data were analyzed with SPSS version 25.0 (IBM, USA). Descriptive statistics (mean $X$ and standard deviation $\mathrm{SD}$ ) were calculated and assumption of distribution normality was verified using the Shapiro-Wilks test. Comparisons within groups between pre- and post-tests were made using the Wilcoxon test for Likert-like scale instruments and physiological tests (HRV). We calculated the effect size of the biserial point correlation (bpc) to quantify the magnitude of changes, and converted the results into Cohen's d, a measure of the effect size as a standardized mean difference, reporting how many standard deviations exist between the two groups compared-experimental group and control group, or the same group before and after the intervention.

The reference points used were: trivial $(d<0.2)$, small $(d=0.2-$ $<0.5)$, moderate $(d=0.5-<0.8)$, large $(d=0.8-1.2)$ and very large $(d>1.2)$. We set the assumed level of statistical significance at $p$ $<0.05$.

The aerobic exercise group included 28 students: all performed the assigned exercises, although only 26 were included in the analysis, as 2 students did not regularly exercise at least 3 days per week. The strength-training group included 26 students, all of whom performed the exercises, but only 25 were included in the analysis, as 1 student did not perform the exercises regularly. The control group comprised 27 students who performed no exercises, and all were included in the analysis (Figure 1, Table 1).[11]

Ethical considerations Students received explanations regarding the nature and aims of the research and informed consent was obtained from each participant. The study was approved by the ethics committee of the National Health Directorate and the Technical University of Ambato, both in Ecuador, under the code: CEISHSOLCAQ.OBS.19.129.

\section{RESULTS}

In the aerobic exercise group, exhaustion showed the greatest change, with a $31 \%$ percent reduction, followed by reduced cynicism $(21.1 \%)$ and academic inefficacy (13.1\%) (Table 1). How- ever, in the strength-training group, the greatest change was obtained in cynicism, with a $27.4 \%$ reduction, followed by inefficacy (a $21.7 \%$ reduction) and exhaustion (a $19.6 \%$ reduction). In the control group, the mean exhaustion level increased by $10.1 \%$. Inefficacy also increased (4.4\%) (Table 1).

The BS dimension showing the greatest reduction over time in the aerobic exercise group was exhaustion, with a moderate effect size $(d=0.532)$, but not cynicism or inefficacy, which exhibited small change effects $(d=0.252$ and 0.397 , respectively). However, in the strength-training group, the dimension with the greatest reduction over time was inefficacy, with a moderate effect size $(d=0.704)$; here the change in exhaustion levels was small $(d=0.299)$ as the change in cynicism $(d=0.315)$. The effect size on exhaustion, cynicism and inefficacy in the control group were all considered trivial $(d=0.128,0.062$ and 0.129 , respectively).

Reduction in HRV is related to mental health problems, overtraining or poor physical condition. In the aerobic exercise group, SDNN had the largest percent change, at $33.0 \%$, while RR and RMSSD had lower percent changes of $16.8 \%$ and $19.7 \%$, respectively.

There was a very large change in effect size in the mean RR in the aerobic and strength groups ( $d=1.281$ and 1.328 respectively), unlike SDNN, which was large $(\mathrm{d}=0.943$ and 0.833$)$, and RMSSD, which was small $(0.425$ and 0.318$)$ in both groups. However, in the control group the effect sizes were small $(0.449,0.457)$ and trivial (0.120) (Table 1).

\section{DISCUSSION}

The study results show that physical exercise reduced BS intensity in participating students, although not all dimensions of BS were reduced considerably. Some of our results coincide with those of other authors: de Vries evaluated the effectiveness of an exercise intervention in reducing $B S$ in patients working in various professions, using a set exercise routine lasting six weeks.[12] The intervention groups reported lower BS than the control group, as was the case in this study.

Table 1: Pre-test and post-test comparison between exercise and control groups

\begin{tabular}{|c|c|c|c|c|c|c|c|c|c|c|c|c|c|}
\hline \multicolumn{6}{|c|}{$\begin{array}{c}\text { Exercise group } \\
\text { Aerobic }(\mathrm{n}=28 ; \mathrm{M} / \mathrm{F}: 11 / 17)^{*}\end{array}$} & \multicolumn{4}{|c|}{$\begin{array}{l}\text { Exercise group } \\
\text { Strength }(\mathrm{n}=26 ; \text { M / F: 10/16)** }\end{array}$} & \multicolumn{4}{|c|}{$\begin{array}{l}\text { Control group } \\
(n=27 ; M / F: 12 / 15)\end{array}$} \\
\hline Variable & & $\begin{array}{c}\text { Pre-Test } \\
\mathbf{X} \text { (SD) }\end{array}$ & $\begin{array}{c}\text { Post-Test } \\
\text { X (SD) }\end{array}$ & $\begin{array}{l}\text { Percent } \\
\text { Change }\end{array}$ & $\begin{array}{l}\text { Effect } \\
\text { size (d) }\end{array}$ & $\begin{array}{c}\text { Pre-Test } \\
\text { X (SD) }\end{array}$ & $\begin{array}{c}\text { Post-Test } \\
\text { X (SD) }\end{array}$ & $\begin{array}{l}\text { Percent } \\
\text { Change }\end{array}$ & $\begin{array}{c}\text { Effect } \\
\text { size (d) }\end{array}$ & $\mid \begin{array}{c}\text { Pre-Test } \\
\text { X (SD) }\end{array}$ & \begin{tabular}{|} 
Post-Test \\
X (SD)
\end{tabular} & $\begin{array}{l}\text { Percent } \\
\text { Change }\end{array}$ & $\begin{array}{l}\text { Effect } \\
\text { size (d) }\end{array}$ \\
\hline \multirow{3}{*}{$\begin{array}{l}\text { Burnout } \\
\text { syndrome }\end{array}$} & Exhaustion & $\begin{array}{r}2.00 \\
(1.24)\end{array}$ & $\begin{array}{r}1.38 \\
(0.99)\end{array}$ & -31.0 & 0.532 & $\begin{array}{r}1.80 \\
(1.19)\end{array}$ & $\begin{array}{r}1.45 \\
(1.11)\end{array}$ & -19.6 & 0.299 & $\begin{array}{r}1.68 \\
(1.27)\end{array}$ & $\begin{array}{r}1.85 \\
(1.31)\end{array}$ & 10.1 & 0.128 \\
\hline & Cynicism & $\begin{array}{r}1.18 \\
(1.03)\end{array}$ & $\begin{array}{r}0.93 \\
(0.97)\end{array}$ & -21.1 & 0.252 & $\begin{array}{r}1.32 \\
(1.12)\end{array}$ & $\begin{array}{r}0.96 \\
(1.22)\end{array}$ & -27.4 & 0.315 & $\begin{array}{r}1.24 \\
(1.22)\end{array}$ & $\begin{array}{r}1.15 \\
(1.69)\end{array}$ & -7.3 & 0.062 \\
\hline & Inefficacy & $\begin{array}{r}4.27 \\
(1.38)\end{array}$ & $\begin{array}{r}3.71 \\
(1.49)\end{array}$ & -13.1 & 0.397 & $\begin{array}{r}4.24 \\
(1.37)\end{array}$ & $\begin{array}{r}3.32 \\
(1.29)\end{array}$ & -21.7 & 0.704 & $\begin{array}{r}4.27 \\
(1.34)\end{array}$ & $\begin{array}{r}4.46 \\
(1.65)\end{array}$ & 4.4 & 0.129 \\
\hline \multirow{3}{*}{$\begin{array}{l}\text { Heart rate } \\
\text { variability }\end{array}$} & $\mathrm{RR}(\mathrm{ms})$ & $\begin{array}{r}865.69 \\
(102.08)\end{array}$ & $\begin{array}{r}1011.37 \\
(128.32)\end{array}$ & 16.8 & 1.281 & $\begin{array}{r}859.92 \\
(100.76)\end{array}$ & $\begin{array}{l}1002.77 \\
(117.92)\end{array}$ & 16.6 & 1.328 & $\begin{array}{r}862.53 \\
(101.24)\end{array}$ & $\begin{array}{r}907.72 \\
(104.05)\end{array}$ & 5.2 & 0.449 \\
\hline & SDNN & $\begin{array}{r}71.32 \\
(20.11)\end{array}$ & $\begin{array}{r}94.87 \\
(29.86)\end{array}$ & 33.0 & 0.943 & $\begin{array}{r}70.34 \\
(20.18)\end{array}$ & $\begin{array}{r}89.92 \\
(27.24)\end{array}$ & 27.8 & 0.833 & $\begin{array}{r}70.91 \\
(21.24)\end{array}$ & $\begin{array}{r}81.13 \\
(24.27)\end{array}$ & 14.4 & 0.457 \\
\hline & RMSSD & $\begin{array}{r}68.71 \\
(31.10)\end{array}$ & $\begin{array}{r}82.24 \\
(33.78)\end{array}$ & 19.7 & 0.425 & $\begin{array}{r}69.75 \\
(31.76)\end{array}$ & $\begin{array}{r}79.81 \\
(32.73)\end{array}$ & 14.4 & 0.318 & $\begin{array}{r}70.01 \\
(30.97)\end{array}$ & $\begin{array}{r}73.69 \\
(31.39)\end{array}$ & 5.3 & 0.120 \\
\hline
\end{tabular}

* The analysis included only 26 participants who performed the exercises regularly.

** The analysis included only 25 participants who performed the exercises regularly.

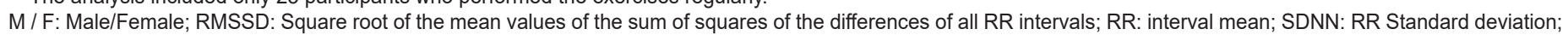
$X(S D)$ : Mean (Standard deviation). 
Eskilsson applied a 12-week aerobic training program of moderate intensity for BS patients.[13] A total of 88 patients diagnosed with BS (average age: 45) were randomly divided into two groups; an intervention group assigned aerobic exercise and a control group with no assignments. The final evaluation showed a decrease in BS levels in the intervention group, with a much smaller decrease in the control group, consistent with our results.

Our study used both strength and aerobic exercise to combat BS, and both types of exercise were found to be effective. It is well known that physical exercise improves blood circulation and, consequently, oxygenation, and stimulates the brain to produce chemical mediators like serotonin, a neurotransmitter that aids in preventing depression. Increased heart rate during exercise strengthens the heart and aids in circulation.[12,13]

One of the possible strengths of this study is the methodology. Exercises assigned to each group followed the latest ACSM recommendations.[10] Another strength is the relationship it draws between mental health and physical exercise, and contributes to the recognition of physical exercise as a therapeutic resource, which has good acceptance among patients and providers, is low-cost, non-pharmacological, and may reduce other risk factors affecting overall health, lifestyle, and wellbeing.

Regarding the study's limitations, we recognize the infeasibility of maintaining the exercise program for longer than initially planned, which would have allowed us to know whether or not there was a change in the intervention's effectiveness over a longer period. Also, tests related to the immune system and inflammationimportant biomarkers for BS effects in human physiology and biochemistry - could not be applied. Furthermore, the true extent of burnout (in both frequency and intensity) was not assessed. It would be useful to scale up the intervention involving physical exercise as a strategy to combat BS in students. This study could provide the initial results necessary to support development of intervention programs using exercise to help combat burnout syndrome in university students.

\section{CONCLUSIONS}

Our results show that physical exercise (aerobic or strength) reduced burnout syndrome levels in university students. - - 1

\section{REFERENCES}

1. Schaufeli WB, Martínez IM, Marques-Pinto A, Salanova M, Bakker AB. Burnout and engagement in university students: a cross-national study. J Cross-Cultural Psychol. 2002 Sep 1;33(5):464-81.

2. Li H, Cheng B, Zhu XP. Quantification of burnout in emergency nurses: a systematic review and meta-analysis. Int Emerg Nurs. 2018 Jul;39:46-54.

3. Kawamura $\mathrm{Y}$, Takayashiki $\mathrm{A}$, Ito $\mathrm{M}$, Maeno T, Seo E, Maeno T. Stress factors associated with burnout among attending physicians: a cross-sectional study. J Clin Med Res. 2018 Mar;10(3):226-32.

4. Boni RADS, Paiva CE, de Oliveira MA, Lucchetti G, Fregnani JHTG, Paiva BSR. Burnout among medical students during the first years of undergraduate school: Prevalence and associated factors. PLoS One. 2018 Mar 7;13(3):e0191746

5. Erschens R, Keifenheim KE, Herrmann-Werner A, Loda T, Schwille-Kiuntke J, Bugaj TJ, et al. Professional burnout among medical students: systematic literature review and meta-analysis. Med Teach. 2018 Feb;41(2):172-83.

6. Azofeifa-Mora CA. Revisión de los beneficios de la intensidad y modalidades de ejercicio físico sobre el estrés psicológico. Pensar Mov. 2018 Apr 18;16(1):1-21. Spanish.

7. Rosales-Ricardo Y, Mocha-Bonilla J, Ferreira JP. Síndrome de Burnout en estudiantes de la
Universidad Técnica de Ambato, Ecuador. Enfermería Investiga. 2020;5(2):37-41. Spanish.

8. Hederich-Martínez C, Caballero-Domínguez C. Validación del cuestionario Maslach Burnout Inventory-Student Survey (MBI-SS) en contexto académico colombiano. Rev CES Psicología. 2016 Jan -Jun;9(1):1-15. Spanish.

9. Bonet J, Parrado E, Barahona A, Capdevila L. Desarrollo y aplicación de un sistema de evaluación combinada de ejercicio físico, de alimentación y de variables psicológicas en jóvenes universitarias. Apunts Medicina de l'Esport. 2016;51(191):75-83. Spanish.

10. American College of Sports Medicine. ACSM's Guidelines for Exercise Testing and Prescription. 10th ed. New York: Wolters Kluwer; 2017.

11. Rosales Ricardo Y. Intervención con ejercicio físico en estudiantes universitarios con síndrome de burnout: un protocolo de estudio. Rev Dilemas Contemp [Internet]. 2020 Apr 1 [cited 2021 Jun 15];7(19):1-22. Available at: https:// doi.org/10.46377/dilemas.v35i1.2240. Spanish.

12. de Vries JD, van Hooff MLM, Geurts SAE, Kompier MAJ. Exercise to reduce work-related fatigue among employees: a randomized controlled trial. Scand J Work Environ Health. 2017 Jul 1;43(4):337-49.

13. Eskilsson T, Slunga Järvholm J, Malmberg Gavelin H, Stigsdotter Neely A, Boraxbekk CJ. Aerobic training for improved memory in patients with stress-related exhaustion: a randomized controlled trial. BMC Psychiatry. 2017 Sep 2;17:322.

\section{THE AUTHORS}

Yury Rosales-Ricardo (Corresponding author: yuryrr82@gmail.com), physical activity and sports specialist with a master's degree in bioenergetic and natural medicine and a doctorate in physical activity and health sciences from the University of Coimbra, Coimbra, Portugal. Adjunct researcher, National Secretariat of Higher Education, Science and Technology (Senescyt), and professor, San Gregorio University Medical School of Portoviejo, Portoviejo, Ecuador. https://orcid.org/0000-0002-0525-2405

José Pedro Ferreira, sports scientist, with a master's degree in motor development and a doctorate in physical activity and health sciences. Professor and researcher, University of Coimbra, Sports Sciences and Physical Education Division, Coimbra, Portugal. https://orcid. org/0000-0002-4427-3276

Submitted: June 6, 2021

Approved for publication: December 16, 2021 Disclosures: None 